\title{
Subjective Well-Being in Non-Obese Individuals in View of Abdominal Fat Distribution and Muscle Mass Index: A General Population Study.
}

\section{Małgorzata Chlabicz}

Medical University of Bialystok: Uniwersytet Medyczny w Bialymstoku

Marlena Paniczko

Medical University of Bialystok: Uniwersytet Medyczny w Bialymstoku Jacek Jamiołkowski

Medical University of Bialystok: Uniwersytet Medyczny w Bialymstoku

\section{Paweł Sowa}

Medical University of Bialystok: Uniwersytet Medyczny w Bialymstoku

\section{Małgorzata Szpakowicz}

Medical University of Bialystok: Uniwersytet Medyczny w Bialymstoku

\section{Magda Łapińska}

Medical University of Bialystok: Uniwersytet Medyczny w Bialymstoku

\section{Andrzej Raczkowski}

Medical University of Bialystok: Uniwersytet Medyczny w Bialymstoku

\section{Wojciech Łaguna}

Bialystok University of Technology: Politechnika Bialostocka

\section{Anna M. Moniuszko-Malinowska}

Medical University of Bialystok: Uniwersytet Medyczny w Bialymstoku

\section{Napoleon Waszkiewicz}

Medical University of Bialystok: Uniwersytet Medyczny w Bialymstoku Irina Kowalska

Medical University of Bialystok: Uniwersytet Medyczny w Bialymstoku Karol A Kamiński ( $\nabla$ fizklin@wp.pl)

Medical University of Bialystok: Uniwersytet Medyczny w Bialymstoku https://orcid.org/0000-00029465-2581

\section{Research}

Keywords: Body composition, Personal satisfaction, Quality of life, Depression

Posted Date: May 11th, 2021 
DOI: https://doi.org/10.21203/rs.3.rs-482840/v1

License: (c) (1) This work is licensed under a Creative Commons Attribution 4.0 International License. Read Full License 


\section{Abstract \\ Background}

While obesity has been correlated with welfare in the general population, there is not much data on the influence of body composition on welfare among the non-obese adult individuals.

\section{Methods}

A longitudinal, population-based study was conducted in 2017-2020. Body composition was assessed using Dual Energy X-ray Absorptiometry. Welfare was rated with Satisfaction with Life Scale (SWLS), Euro Quality of Life Visual Analogue Scale (EQ-VAS) and Beck Depression Inventory (BDI).

\section{Results}

A total of 726 non-obese individuals from general population were analyzed. The mean age was $46.8 \pm$ 15.4 years and $42.1 \%$ of participants were male. The mean value for SWLS was $23.09 \pm 5.43$, for EQ-VAS was $78.0 \pm 14.5$, and for BDI was $6.7 \pm 6.6$. On SWLS the waist-hip ratio had a negative impact even after adjustment for age, gender and concomitant diseases. EQ-VAS was inversely associated with android fat distribution and directly associated with muscle mass. BDI value was inversely associated with lower muscle mass, especially of the lower limbs. The well-being of women was mainly associated with the distribution of adipose tissue and less with the distribution of muscle tissue - abdominal fat distribution has a particularly negative impact on well-being among women. In contrast, men's well-being depends more on muscle mass and to a lesser extent on the distribution of fat tissue - a positive significant effect has lean mass and a circumference of thigh below gluteal fold.

\section{Conclusions}

Body composition is significantly associated with welfare in non-obese population. Android type fat distribution may have a negative impact while muscle mass positive.

\section{Introduction}

Life satisfaction (LS) is the goal of human development and is very important to subjective well-being and psychosocial functioning (1), due to that well-being assessment is an important scientific task. The Satisfaction With Life Scale (SWLS) was developed in 1959 by Diener (2) to measure the cognitive aspect of subjective well-being. Euro Quality of Life Visual Analogue Scale (EQ-5D) was designed to measure health related quality of life (HRQL). Depression is the most common psychiatric disorder, which is related to life satisfaction. The most common scale used to asses this disorder is the Beck Depression Inventory (BDI) (3). 
Several previous studies have shown obesity to be related to deterioration in LS (4, 5), HRQL (6-8) and severity of depression (9-11). While obesity has been correlated with welfare in the general population, there is not much data on the influence of body composition on welfare among the non-obese adult individuals. We hypothesized that the body composition could be related with LS, HRQL and severity of depression syndrome.

\section{Aim of the Study}

We aimed to investigate the relationship between body composition and subjective well-being in nonobese adult individuals from the general population using Satisfaction with Life Scale (SWLS), Euro Quality of Life Visual Analogue Scale (EQ-VAS) and Beck Depression Inventory (BDI).

\section{Patients And Methods}

\section{Study Population}

The study was conducted in 2017-2020 in a representative sample of area residents aged 20-79. 2449 residents randomly selected from the mayor's office database were invited to participate in the study and 966 individuals were examined. Due to obesity (body mass index: $\mathrm{BMI} \geq 30 \mathrm{~kg} / \mathrm{m}^{2}$ ), 240 individuals were excluded from further analysis. As a result, 726 people (mean age $46.76 \pm 15.36$ years, $42.1 \%$ male) were included in the research group.

\section{Data Collection and Assays}

Data was collected through standardized health examinations in specially equipped examination center. Details of the subjects' medical history were collected from questionnaires. The anthropometric measurements were done, including height, weight, circumferences of waist, hips, thigh (just below the buttock fold) using SECA 201 tape (SECA, Hamburg, Germany) with participants wearing light clothing without shoes. Measurements were performed in accordance with the World Health Organization (WHO) guidelines (12). The waist to hips ratio (WHR) was calculated as ratio between waist and hips circumference. Body mass index (BMI) was calculated as weight in kilograms divided by height in meters squared. The blood pressure (BP) was measured while the participants were seated after a minimum rest period of 5 minutes using oscillometeric method applying Omron Healthcare Co., Ltd MG Comfort (HEALTHCARE Co., Ltd. Terado-cho, Muko, Kyoto, Japan). The body composition was measured by dual energy x-ray absorptiometry (DEXA) (GE Healthcare, Chicago, Illinois, USA). The gynoid (G) fat (GF) and lean (GL), android (A) fat (AF) and lean (AL), legs (L) fat (LF) and lean (LL) were measured automatically as described previously $(13,14)$. Fat mass index (FMI), lean mass index (LMI) and visceral mass index (VMI) were calculated as fat, lean and visceral mass in kilograms divided by height in meters squared. The AF/GF ratio was calculated between the fat of the android and fat of the gynoid regions. The GF/total fat (GF/TF) ratio was calculated as ratio between the gynoid fat and total fat. The AF/total fat 
(AF/TF) ratio was calculated as ratio between the android fat and total fat. The legs fat/total fat (LF/TF) ratio was calculated as ratio between the leg fat and total fat. Analogously the ratio of lean $\mathrm{GL} /$ total lean $(\mathrm{GL} / \mathrm{TL}), \mathrm{AL} /$ total lean $(\mathrm{AL} / \mathrm{TL}$ ) and legs lean/total lean (LL/TL) were calculated. The Satisfaction with Life Scale (SWLS) (15) has been used as a measure of the life satisfaction component of subjective wellbeing. The SWLS has good validity, related to but still separate from constructs such as depression, negative and positive effects, self-esteem, anxiety, and psychological distress. Scores on the SWLS have been shown to correlate with measures of mental health and be predictive of future behaviors. The scale is a 5 -item questionnaire rated on a 7-point scale from 1 - strongly disagree to $7-$ strongly agree. The possible range of scores is $5-35$, with a score of 20 representing a neutral point on the scale. Scores between 5-9 indicate that a respondent is extremely dissatisfied with life, whereas scores between 3135 indicate that a respondent is extremely satisfied. Euro Quality of Life Visual Analogue Scale (EQ-5D) was designed to measure health related quality of life. This instrument is widely used in the health sector: in patient-reported outcome exercises, in population heath studies, and in health technology assessment (16). Visual Analogue Scale (EQ-VAS) is the second part of the questionnaire, asking to mark health status on the day of the interview on a $20 \mathrm{~cm}$ vertical scale with end points of 0 and 100 . The bottom rate (0) corresponds to " the worst health you can imagine", and the highest rate (100) corresponds to "the best health you can imagine". This information can be used as a quantitative measure of health outcome as judged by the individual respondents. Depression symptoms were assessed by the Beck Depression Inventory (3) (BDI), a self-report measurement to assess severity of depression. The scale comprises of 21 questions, each one with four answer options. Each answer being scored on a scale value of 0 to 3 . Higher total scores indicate more severe depressive symptoms.

\section{Statistical analysis}

Descriptive statistics for quantitative variables were presented as means and standard deviations and as counts and frequencies for qualitative variables. Comparisons of continuous variables between subgroups were conducted using Mann-Whitney or Fisher's tests. Associations between SWLS, EQ-VAS, BDI scales and body composition variables were analyzed by gender using simple and multiple linear regression models. Multiple linear regression models included single variables listed in the tables and were adjusted for age (Model 1), for age, history of cardiovascular disease (CVD) (i.e. arterial hypertension $(\mathrm{AH})$, atrial fibrillation (AF), myocardial infarction (MI), coronary heart disease (CHD), peripheral artery disease (PAD), stroke) and history of diabetes mellitus (DM) (Model 2) or for age and WHR (Model 3). The charts present standardized plots of the regression equation with $95 \%$ confidence intervals. Statistical hypotheses were verified at 0.05 significance level. The IBM SPSS Statistics 20.0 statistical software (Armonk, NY, USA) was used for all calculations.

\section{Results}

The baseline characteristics of the study population are summarized in Table 1 . The mean age was 46.8 \pm 15.4 years and $42.1 \%$ participants were men. The mean value for SWLS was $23.1 \pm 5.4$, for EQ-VAS was $77.9 \pm 14.5$, and for BDI was $6.7 \pm 6.6$. The mean BMI was $24.6 \pm 3.1,51.9 \%$ of population were of normal 
weight and $48.1 \%$ were overweight. The characteristics of participants according sex are presented in Table 1. There was no statistically significant difference between the genders in relation to the SWLS value $(p=0.06)$, while a statistically significantly higher value of EQ-VAS was found in the group of men and the BDI in the group of women, $p<0.001$ and $p<0.001$, respectively. Height, weight and waist circumference were significantly higher in men group than in women. There was no statistically significant difference between genders regarding the hips and thighs circumferences. Regression analysis was next used to evaluate the relationship among anthropometric variables or body composition analysis and well-being scales. The analysis was performed in gender disaggregated populations. The most significant variables are presented in Figs. 1, 2 and 3. 
Table 1

Characteristics of the non-obese general population

\begin{tabular}{|c|c|c|c|c|}
\hline Variable & $\begin{array}{l}\text { Total } \\
\text { population } \\
n=726\end{array}$ & $\begin{array}{l}\text { Women } \\
n=420\end{array}$ & $\begin{array}{l}\text { Men } \\
n=306\end{array}$ & P-values* \\
\hline Age, years & $46.76 \pm 15.36$ & $47.48 \pm 15.29$ & $45.78 \pm 15.43$ & 0.11 \\
\hline SWLS & $23.09 \pm 5.43$ & $22.79 \pm 5.57$ & $23.49 \pm 5.22$ & 0.06 \\
\hline EQ-VAS & $77.95 \pm 14.49$ & $76.42 \pm 14.83$ & $80.03 \pm 13.80$ & $<0.001$ \\
\hline BDI & $6.66 \pm 6.55$ & $7.45 \pm 6.69$ & $5.58 \pm 6.21$ & $<0.001$ \\
\hline BPs, mmHg & $\begin{array}{l}121.56 \pm \\
16.62\end{array}$ & $\begin{array}{l}116.22 \pm \\
15.78\end{array}$ & $\begin{array}{l}128.91 \pm \\
14.86\end{array}$ & $<0.001$ \\
\hline BPd, mmHg & $80.22 \pm 9.42$ & $78.59 \pm 8.90$ & $82.46 \pm 9.90$ & $<0.001$ \\
\hline $\mathrm{HR}, \mathrm{bpm}$ & $72.08 \pm 10.60$ & $72.75 \pm 10.49$ & $71.15 \pm 10.70$ & 0.14 \\
\hline \multicolumn{5}{|c|}{ Anthropometric measurements and body composition analysis } \\
\hline Height, cm & $170.23 \pm 9.56$ & $164.48 \pm 6.36$ & $178.12 \pm 7.33$ & $<0.001$ \\
\hline Weight, kg & $71.64 \pm 12.69$ & $64.65 \pm 8.74$ & $81.23 \pm 10.88$ & $<0.001$ \\
\hline Waist, cm & $81.97 \pm 10.63$ & $76.64 \pm 8.38$ & $89.32 \pm 8.89$ & $<0.001$ \\
\hline Hip, cm & $95.99 \pm 7.11$ & $95.83 \pm 7.63$ & $96.20 \pm 6.32$ & 0.47 \\
\hline Thigh, cm & $56.40 \pm 4.79$ & $56.19 \pm 4.92$ & $56.69 \pm 4.59$ & 0.11 \\
\hline $\mathrm{BMI}, \mathrm{kg} / \mathrm{m}^{2}$ & $24.62 \pm 3.11$ & $23.93 \pm 3.18$ & $25.56 \pm 2.76$ & $<0.001$ \\
\hline $\mathrm{BMI}<25 \mathrm{~kg} / \mathrm{m}^{2}$ & $377(51.92)$ & $260(62)$ & $117(38)$ & $<0.001$ \\
\hline BMI $25-29.99 \mathrm{~kg} / \mathrm{m}^{2}$ & $349(48.07)$ & $160(38)$ & $189(62)$ & $<0.001$ \\
\hline WHR & $0.85 \pm 0.09$ & $0.80 \pm 0.07$ & $0.93 \pm 0.07$ & $<0.001$ \\
\hline WHR, $\geq 0.85$ women, $\geq 0.9$ men & $299(41.18)$ & $94(22)$ & $205(67)$ & $<0.001$ \\
\hline Lean Mass Index, (kg/m2) & $16.10 \pm 2.02$ & $14.80 \pm 1.25$ & $17.86 \pm 1.45$ & $<0.001$ \\
\hline Fat Mass Index, $\left(\mathrm{kg} / \mathrm{m}^{2}\right)$ & $7.77 \pm 2.37$ & $8.40 \pm 2.34$ & $6.91 \pm 2.13$ & $<0.001$ \\
\hline Android fat mass, $\mathrm{kg}$ & $1.91 \pm 0.88$ & $1.72 \pm 0.75$ & $2.17 \pm 0.97$ & $<0.001$ \\
\hline Gynoid fat mass, kg & $3.60 \pm 1.05$ & $3.98 \pm 0.98$ & $3.08 \pm 0.91$ & $<0.001$ \\
\hline Gynoid lean mass, kg & $7.0 \pm 1.51$ & $5.96 \pm 0.69$ & $8.43 \pm 1.11$ & $<0.001$ \\
\hline Legs fat mass, $\mathrm{kg}$ & $6.89 \pm 2.18$ & $7.85 \pm 2.00$ & $5.60 \pm 1.67$ & $<0.001$ \\
\hline
\end{tabular}




\begin{tabular}{|c|c|c|c|c|}
\hline Variable & $\begin{array}{l}\text { Total } \\
\text { population } \\
n=726\end{array}$ & $\begin{array}{l}\text { Women } \\
n=420\end{array}$ & $\begin{array}{l}\text { Men } \\
n=306\end{array}$ & P-values* \\
\hline Legs lean mass, kg & $16.16 \pm 3.66$ & $13.71 \pm 1.85$ & $19.51 \pm 2.76$ & $<0.001$ \\
\hline AF/GF & $0.54 \pm 0.22$ & $0.42 \pm 0.15$ & $0.69 \pm 0.21$ & $<0.001$ \\
\hline GF/TF & $0.16 \pm 0.07$ & $0.16 \pm 0.07$ & $0.15 \pm 0.08$ & $<0.001$ \\
\hline $\mathrm{AF} / \mathrm{TF}$ & $0.08 \pm 0.06$ & $0.07 \pm 0.04$ & $0.10 \pm 0.07$ & $<0.001$ \\
\hline LF/TF & $0.30 \pm 0.14$ & $0.32 \pm 0.14$ & $0.27 \pm 0.14$ & $<0.001$ \\
\hline $\mathrm{GL} / \mathrm{TL}$ & $0.15 \pm 0.05$ & $0.13 \pm 0.03$ & $0.18 \pm 0.05$ & $<0.001$ \\
\hline LL/TL & $0.34 \pm 0.11$ & $0.29 \pm 0.08$ & $0.42 \pm 0.11$ & $<0.001$ \\
\hline \multicolumn{5}{|l|}{ History } \\
\hline History of hypertension & $156(21.49)$ & $92(22)$ & $64(21)$ & 0.99 \\
\hline History of diabetes & $29(3.99)$ & $20(5)$ & $9(3)$ & 0.22 \\
\hline History of atrial fibrillation & $18(2.48)$ & $8(2)$ & $10(3)$ & 0.24 \\
\hline History of myocardial infarction & $14(1.93)$ & $3(1)$ & $11(4)$ & 0.005 \\
\hline History of coronary heart disease; & $15(2.07)$ & $6(1)$ & $9(3)$ & 0.155 \\
\hline $\begin{array}{l}\text { History of peripheral artery } \\
\text { disease }\end{array}$ & $7(0.96)$ & $4(1)$ & $3(1)$ & 0.96 \\
\hline History of stroke & $10(1.38)$ & $3(1)$ & $7(2)$ & 0.07 \\
\hline Currently smoking & $147(20.85)$ & $66(16)$ & $81(27)$ & $<0.001$ \\
\hline History of hypertension & $156(21.49)$ & $92(22)$ & $64(21)$ & 0.99 \\
\hline \multicolumn{5}{|c|}{$\begin{array}{l}\text { The data is shown as } n(\%) \text {, mean } \pm \text { SD. SD: standard deviation; SWLS: Satisfaction With Life Scale; } \\
\text { EQ-VAS: Euro Quality of Life Visual Analogue Scale; BDI: Beck Depression Inventory; BPs: systolic } \\
\text { blood pressure, BPd: diastolic blood pressure, mmHg: millimeters of mercury; HR: heart rate; bpm: } \\
\text { beats per minute; BMI: body mass index; kg: kilogram; m2: square meter; WHR: waist-hip ratio; AF/GF: } \\
\text { android fat/gynoid fat; GF/TF: gynoid fat/total fat; AF/TF: android fat/total fat; LF/TF: legs fat/total } \\
\text { fat; GL/TL: gynoid lean/total lean; LL/TL: legs lean/total lean. }\end{array}$} \\
\hline \multicolumn{5}{|c|}{ *P-values for comparing men and women } \\
\hline
\end{tabular}

\section{Women population}

In women population, a significant negative association between SWLS and android fat distribution parameters (WHR, circumference of waist, VMI, AF, AF/GF, AF/TF) was observed while height and gynoid lean mass (GL) were positively associated with SWLS. After adjustment for age (Model 1), only the relation between SWLS and WHR remained significant. Finally, WHR had negative effect on SWLS even 
after adjustment for age and comorbidities (Model 2). After adjustment for age and WHR (Model 3), GF/TF presented a negative impact on SWLS. EQ-VAS showed a significant negative association with age, weight, BMI, FMI, LMI and android fat distribution parameters (WHR, circumference of waist, VMI, AF, AF/GF, AF/TF). While height was positively associated with EQ-VAS. The negative association between EQ-VAS and BMI, FMI, abdominal fat distribution (WHR, circumference of waist, VMI, AF, AF/GF) remained significant after adjustment for age (Model 1). Finally, FMI and android fat distribution parameters (WHR, circumference of waist, VMI, AF, AF/GF) were inversely associated with even EQ-VAS after adjustment for age and history of CVD and DM (Model 2). In Model 3, FMI and android fat distribution parameters (VMI, AF) remain significantly associated after adjustment for age and WHR. With BDI scoring, positively associated were age and android fat distribution parameters (WHR, circumference of waist, VMI, AF/GF, $A F / T F$ ), while height and lean mass parameters (LL, GL, GL/TL, LL/TL) presented a significant negative association with BDI scoring. In Model 1, the positive association between BDI and WHR and inverse association with GL/TL, LL/TL remained significant. However, in Model 2 and Model 3, only GL/TL and LL/TL remained significant. The details are presented in Supplementary material (Tables S1, S3, S5 and S7).

\section{Men population}

In men population, no association was found between SWLS and investigated variables in univariate analysis. After adjustment for age (Model 1) and age with comorbidities (Model 2), only WHR was inversely associated with SWLS while after adjustment for age and WHR (Model 3), a positive association was found with a larger silhouette (BMI, FMI, AF) and thigh circumference. In contrast, with EQ-VAS, several parameters of anthropometric measurement and body composition measured by DEXA were significantly related. A negative relationship was found with android fat distribution parameters (WHR, waist, VMI, AF, AF/GF, AF/TF) while a positive relationship was found with the parameters of muscle tissue ( $L M I)$, especially of the legs ( $L L, G L, G L / T L, L L / T L)$. In Model 1, the inverse association between EQ-VAS and android fat distribution parameters (AF/TF) remained significant after adjustment for age. Also, a positive association between EQ-VAS and LMI, GL, GL/TL remained significant. Moreover, appeared GF/TF, LF/TF negatively correlated with EQ-VAS. Finally, thigh circumference, parameters of muscle mass (LMI) and leg muscle mass (GL, GL/TL) were positively associated; and leg fat (LF/TF) negatively associated with EQ-VAS even after adjustment for age and history of CVD and DM (Model 2.). In Model 3, the parameters of muscle mass ( $L M I)$, especially of the legs ( $L L, G L, G L / T L, L L / T L$ and thigh circumference) became more important. As shown in Table S2, a significant negative association between $B D I$ value, muscle mass ( $A L, G L, G L / T L)$ and thigh circumference has been found. In Model 1 , Model 2 and Model 3, thigh circumference, AL, GL, GL/TL remained inversely associated with BDI value. The details are presented in Supplementary material (Tables S4, S6 and S8).

To disentangle the independent relationships of body composition in non-obese individuals with subjective well-being from any additional confounding diseases, another sub analysis was performed (Supplementary materials). From above analyzed population, we excluded people with a history of CVD $(\mathrm{AH}, \mathrm{MI}, \mathrm{CHD}, \mathrm{PAD}$ and stroke), $\mathrm{AF}$, heart failure (HF), DM, chronic obstructive pulmonary disease (COPD), 
asthma, cancer, chronic kidney disease (CKD) with glomerular filtration rate (GFR) $<60 \mathrm{ml} / \mathrm{min}$, and any mental disorders. The baseline characteristics of this subpopulation are summarized in Table S9. In the univariate analysis in the group of women, very similar parameters were related to the scales, no new statistically significant parameters appeared. In Model 1, more parameters of android fat distribution associated with subjective well-being. Namely, SWLS scores were negatively associated with VTI (B -0.833, $p=0.005), A F / G F(B-9.323, p=0.003)$ and AF/TF $(B-25.418, p=0.010)$. However, in men, the relationship between well-being and higher muscle mass was even more pronounced, there were new significant positive relationships with SWLS: the thigh circumference, the hip circumference and gynoid lean mass. After taking into account the age and gender, WHR (B -15.819; $p=0.001)$ remained negatively significant in relation to SWLS, with concomitant positive relation with thigh circumference $(B) 0.236, p=$ 0.009). Similarly, in the EQ-VAS analysis in men, an additional strong positive link appeared with thigh circumference in Model 1. In depression analysis in men, a stronger negative link with low muscle mass, especially the lower limbs was underlined. In conclusion, in this sub-population, comparable factors in women were associated with subjective well-being, while in men, a more positive relationship with thigh circumference was emphasized. Detailed analyses can be found in the Supplementary materials (Tables S10, S11, S12 and S13).

\section{Discussion}

The present study reports that body composition has an impact on well-being in non-obese individuals from general population. We observed that different dimensions are related to different well-being data measures and gender. WHR had the greatest negative impact on life satisfaction (SWLS) even after adjustment for age, gender and concomitant diseases. Health related quality of life (EQ-VAS) was inversely associated with android fat distribution and directly associated with muscle mass, especially of the lower limbs. Depressive symptoms (assessed by BDI) were associated with lower muscle mass, especially of the lower limbs. The well-being of women associated mainly with the distribution of adipose tissue and less on the distribution of muscle tissue - abdominal fat distribution has a particularly negative impact on well-being among women. In contrast, men's well-being depends more on muscle mass and, to a lesser extent, on the distribution of fat tissue.

\section{Life Satisfaction}

LS is a crucial indicator of people's quality of life and reflects a subjective judgment on the quality of life based on individual criteria for happiness and success. Previous research has established a negative influence of obesity on subjective well-being (4). The results from Forste and Moore (5) indicate lower LS among adolescents that are overweight and obese relative to normal weight youth, and perceptions of body weight are generally more strongly associated with low LS among girls compared to boys. In the current study, we showed similar results regarding gender. In the group of men none of the analyzed parameters influenced LS in the univariate analysis, only after correction for age we showed a negative impact of WHR on LS. Rosmond et al. (17) in univariate analyses showed that BMI and WHR correlated with symptoms of depression and anxiety, sleep disturbances, psychosomatic disease as well as the 
degree of life satisfaction. When adjusted for WHR, all significant relationships with BMI disappeared. In contrast, the WHR, adjusted for BMI, showed remaining significant associations with the use of anxiolytics, hypnotics, antidepressive drugs, degree of melancholy and life satisfaction $(p=0.002$, negative) and dyspepsia $(p<0.001)$. It was concluded that in contrast to BMI, the WHR is associated with symptoms of depression and anxiety with associated sleep disturbances as well as psychosomatic symptoms and dissatisfaction. The researchers obtained similar results in both groups of men and women (18). It was hypothesized that the mechanism involved might be increased secretion of cortisol, directing storage fat to central adipose tissue depots. A study by Tang et al. (19) confirmed that cortisol levels were inversely related to psychological quality of life. The results indicate that activity of the hypothalamic-pituitary-adrenal (HPA) axis is linked to LS. In our study, the WHR had the greatest negative association with LS, which may suggest such a relationship also in the non-obese population, regardless of gender.

Moreover, in multivariate analysis adjusted by age and WHR, we demonstrated a positive association of a larger silhouette (BMI, FMI, android fat mass and thigh circumference) with LS in men. Calzo et al. (20) showed, that the desire for bigger muscles increased slightly each year across adolescent males $(\beta=.10$, $95 \%$ C.I. $=.09, .11$ ), and attempts to gain weight increased three-fold across adolescence, with up to $30 \%$ reporting weight gain attempts by age 16 . While media images and advertisements reinforce the notion that thinness is central to women's physical attractiveness, content analyses have demonstrated that boys and men are inundated with images of unattainable muscularity $(21,22)$.

In women, the multiple parameters of the abdominal fat distribution influenced LS, and WHR remained the most important factor after adjusting for age, history of CVD and DM. Simultaneously, in multivariate analysis adjusted by age and WHR, we demonstrated a negative effect of gynoid fat (G/TF). As mentioned above, the media often reinforce the message that slenderness is a symbol of attractiveness and beauty. That could serve as a reason for higher body dissatisfaction even in non-obese women with gynoid fat distribution.

To the best of our knowledge, this is the first analysis to show a relationship between WHR and LS in both genders in non-obese individuals from general population followed by a positive association with a larger silhouette in men, and a negative association with gynoid adipose distribution in women using WHR as a covariate.

\section{HRQL}

Several studies showed a negative impact of obesity on $\operatorname{HRQL}(6,23,24)$. In current non-obese population, the EQ-VAS value was inversely associated with android fat distribution and directly associated with muscle mass, especially of the lower limbs. The relationship between android fat distribution and HRQL would be explained similarly to LS. Increasingly, HRQL is considered to be an important outcome of care for HPA axis dysregulation. Bucy et al. (25) showed that hypercortisolism had the greatest negative influence on HRQL with pituitary and benign adrenal causes of Cushing's syndrome and primary adrenal insufficiency patients. The relationship between muscle mass and HRQL has also 
been shown by other researchers, but in different populations. Kim et al. (26) investigated the relationship between involuntary weight loss with low muscle mass and HRQL in a large representative sample of older adults. HRQL was measured using the EuroQol 5-dimension (EQ-5D) instrument. This survey showed that involuntary weight loss combined with low muscle mass was more closely associated with poor HRQL than involuntary weight loss alone in older adults. Balogun et al. (27) described the associations of low muscle mass, handgrip and lower-limb muscle strength with HRQL in older adults. Participants with lower limb muscle strength $(\beta=-0.061,95 \% \mathrm{Cl}:-0.089,-0.033)$ and women $(\beta=-0.089$, $95 \% \mathrm{Cl}:-0.129,-0.049)$ with lower handgrip had clinically meaningful reductions in HRQoL compared to those with normal strength. We confirmed the strong positive relationship between muscle mass and HRQL, especially of the lower limbs, in both genders, but more pronounced in men. However, in women HRQL was negatively influenced to a greater extent by the abdominal distribution of adipose tissue.

\section{Depression}

Body composition is presumed to play an important role in the genesis of mental disorders like depression. Several studies showed a correlation between obesity and depression $(9-11,28)$. Koksal et al. (11) showed that body fat percentage had the highest correlation with depression severity in obese patients, however positive association was found with BMI, waist circumference, hip circumference, visceral fat percentage (11). Speed et al. (10), using Mendelian randomization, showed that fat mass and short stature are causal risk factors for depression. Other study in overweight and obese individuals with metabolic syndrome showed that a higher percentage of body fat and lower total lean mass were associated with an increased severity of depression and anxiety (29). The authors hypothesized that an increase in lean mass may indicate healthier individuals. In our study, short stature was a risk factor for depression only in women using univariate regression analysis. We did not show a relationship between the severity of depression and BMI or FMI, but with an android fat distribution in women and low muscle mass in both sexes regardless of the comorbidities. This observation is consistent with previous work by Moon et al. (30), which reported that girls with decreased muscle mass had a greater tendency for a depressed mood compared to girls with optimal muscle mass $(P=0.023)$. After adjusting for age, WHR, smoking status, alcohol consumption, frequency of physical activity, self-reported obesity, weight-loss efforts and monthly household income, girls with low muscle mass were 2.60 times more at risk of developing depression than girls with normal muscle mass (95\% confidence interval $[\mathrm{Cl}], 1.05-6.49 ; \mathrm{P}=$ 0.040). Likewise, Heo et al. (31) showed the independent association between low skeletal muscle mass and depressive symptoms in middle-aged men. Noh and Park (32) examined participants being aged 65 years or older $(n=3,219)$, and showed that for men, handgrip strength and relative handgrip strength were inversely associated with risk of stress, depressed mood, and suicidal ideation. The biological pathways are known to affect a decline in muscle mass and brain function. Brain-derived neurotrophic factor (BDNF) drives neurogenesis in the hippocampus and is produced in skeletal muscle (33). A decreased contraction of skeletal muscle can cause a decline in secretion of BDNF as well as volume reduction of the hippocampus and thus, has been implicated in psychiatric illness (34). Furthermore, inflammation and oxidative stress are common pathophysiology of reduced muscle mass and cause depression. The activity of skeletal muscle boosts the immune system, and its redox effects reduce muscle catabolism 
and maintain mood (35). On the other hand, we showed that in female WHR was significantly associated with depression. It seems that different aspects of depression have abdominal fat distribution in female population. Alshehri et al. (36) in the Netherlands Epidemiology of Obesity (NEO) study (6671 middleaged individuals with BMI of $27 \mathrm{~kg} / \mathrm{m}^{2}$ or higher) showed that overall and abdominal adiposity measures were associated with a depressive mood. Rivenes et al. (37) in the HUNT-2 study analyzed 65,648 adults between 20 and 89 years of age; and showed that elevated WHR was associated with an increased prevalence of depression. After adjustment for BMI, physical activity, social isolation, and somatic diseases, WHR remained independently associated with depression in both males and females. A clinical implication of this finding was that abdominal fat distribution appears to be the key mediator in the relationship between obesity and depression, and increased BMI was not independently associated with depression. The authors conclude that these findings were consistent with a hypothesis that links obesity and depression via metabolic disturbances involving the HPA axis. In the current study, we were able to detect a negative association between lower lean mass and a related circumference of thigh and depressive mood in men; whereas android fat distribution and lower muscle mass of legs in women. These results may imply that various factors of body composition play a crucial role in relation to depression in a non-obese population categorized by gender.

\section{Population}

Overall, 240 individuals with obesity $(\mathrm{BMI} \geq 30 \mathrm{~kg} / \mathrm{m} 2)$ were excluded from our research. Because being overweight did not significantly affect $\mathrm{HRQL}$ scores (38), we did not exclude overweight participants from the study. In order to disentangle the independent relationships of body composition in non-obese individuals with subjective well-being from any additional confounding diseases, another sub analysis was performed, confirming our prior analysis. Therefore, not other diseases that negatively affect wellbeing but body composition is significantly associated with welfare.

\section{Limitations}

There are some limitations associated with the present study. Firstly, this study is limited to a sample from an urban environment, and a relatively low (41.7\%) participation rate could have affected the representativeness of the study. Secondly, to analyze the quality of life, only visual analogue scale presenting the second part of the Euro Quality of Life Visual Analogue Scale (EQ-5D) (EQ-VAS) was used.

\section{Conclusions}

Our main findings point out that the body composition has an impact on well-being in non-obese individuals from general population. These associations differ depending on particular aspect of selfreported well-being and gender. Abdominal obesity measured by WHR has the greatest negative impact on life satisfaction even after adjustment for age, gender and concomitant diseases. Health related quality of life is inversely associated with android fat distribution and directly associated with muscle mass. BDI value is associated with low muscle mass, especially of the lower limbs. The well-being of 
women is associated mainly with the distribution of adipose tissue and less on the distribution of muscle tissue - abdominal fat distribution has a particularly negative impact. In contrast, men's well-being depends more on muscle mass and, to a lesser extent, on the distribution of fat tissue.

\section{Abbreviations}

$\mathrm{A}$ : android; $\mathrm{AF}$ : android fat; $\mathrm{AF}$ : atrial fibrillation, $\mathrm{AH}$ : arterial hypertension, $\mathrm{AL}$ : android lean; $\mathrm{BDI}$ : Beck Depression Inventory; BMI: body mass index; BP: blood pressure; CHD: coronary heart disease; CKD: chronic kidney disease; COPD chronic obstructive pulmonary disease; CVD: cardiovascular disease; DEXA: dual energy x-ray absorptiometry; DM: diabetes mellitus; EQ-5D: Euro Quality of Life Visual Analogue Scale; FMl: fat mass index; G: gynoid; GF: gynoid fat; GL: gynoid lean; GFR: glomerular filtration rate; HF: heart failure; HPA: hypothalamic-pituitary-adrenal; HRQL: health related quality of life; L: legs; LF: legs fat; LL: legs lean; LMI: lean mass index; LS: Life satisfaction; MI: myocardial infarction; PAD: peripheral artery disease; SWLS: Satisfaction With Life Scale; TF: total fat; TL; total lean; WHO: World Health Organization; WHR: waist to hips ratio; VMI: visceral mass index.

\section{Declarations}

\section{Acknowledgment}

The authors thank Natalia Zajaczkowska for language corrections.

\section{Authors' contributions}

MC, MP and KAK conceptualization; AR and KAK data curation; MP, JJ and Wt formal analysis; MC, MP, Mt, MS and PS investigation; MC, MP, JJ, PS and KAK methodology; MC and MP writing- original draft; AMMM, NW, IK and KAK review and editing. All authors read and approved the final manuscript.

\section{Funding}

This research was supported by the Municipal Office in Bialystok, Poland, grant number W/UB/DSP/1640/UMBIAŁYSTOK/2017 and from statutory funds from Medical University of Bialystok for Bialystok PLUS study, grant number N/ST/ZB/18/001/1145.

\section{Availability of data and materials}

All data sets analyzed during the study that were not presented in the text are available to the correspondent upon request.

\section{Ethics approval and consent to participate}

Ethical approval for this study was provided by the local Ethics Committee (approval number: R-I002/108/2016). The study was conducted in accordance with the Declaration of Helsinki and all 
participants gave written informed consent.

\section{Consent for publication}

Not applicable.

\section{Competing interests}

The authors declare that they have no conflict of interest.

\section{References}

1. Seligman ME, Csikszentmihalyi M. Positive psychology. An introduction. Am Psychol. 2000;55(1):514.

2. Diener E, Emmons RA, Larsen RJ, Griffin S. The Satisfaction With Life Scale. J Pers Assess. 1985;49(1):71-5.

3. Beck AT, Steer RA, Carbin MG. Psychometric properties of the Beck Depression Inventory: Twenty-five years of evaluation. Clinical Psychology Review. 1988;8(1):77-100.

4. Habibov N, Auchynnikava A, Luo R, Fan L. A healthy weight improves life satisfaction. Int J Health Plann Manage. 2019;34(1):396-413.

5. Forste R, Moore E. Adolescent obesity and life satisfaction: perceptions of self, peers, family, and school. Econ Hum Biol. 2012;10(4):385-94.

6. Cameron AJ, Magliano DJ, Dunstan DW, Zimmet PZ, Hesketh K, Peeters A, et al. A bi-directional relationship between obesity and health-related quality of life: evidence from the longitudinal AusDiab study. Int J Obes (Lond). 2012;36(2):295-303.

7. Daviglus ML, Liu K, Yan LL, Pirzada A, Garside DB, Schiffer L, et al. Body mass index in middle age and health-related quality of life in older age: the Chicago heart association detection project in industry study. Arch Intern Med. 2003;163(20):2448-55.

8. Yancy WS, Jr., Olsen MK, Westman EC, Bosworth HB, Edelman D. Relationship between obesity and health-related quality of life in men. Obes Res. 2002;10(10):1057-64.

9. Vogelzangs N, Kritchevsky SB, Beekman AT, Newman AB, Satterfield S, Simonsick EM, et al. Depressive symptoms and change in abdominal obesity in older persons. Arch Gen Psychiatry. 2008;65(12):1386-93.

10. Speed MS, Jefsen $\mathrm{OH}$, Borglum AD, Speed D, Ostergaard SD. Investigating the association between body fat and depression via Mendelian randomization. Transl Psychiatry. 2019;9(1):184.

11. Koksal UI, Erturk Z, Koksal AR, Ozsenel EB, Kaptanogullari OH. What is the Importance of Body Composition in Obesity-related Depression? Eurasian J Med. 2017;49(2):102-6.

12. Cantor WJ, Fitchett D, Borgundvaag B, Heffernan M, Cohen EA, Morrison LJ, et al. Rationale and design of the Trial of Routine ANgioplasty and Stenting After Fibrinolysis to Enhance Reperfusion in Acute Myocardial Infarction (TRANSFER-AMI). Am Heart J. 2008;155(1):19-25. 
13. Chlabicz M, Jamiolkowski J, Paniczko M, Sowa P, Lapinska M, Szpakowicz M, et al. Independent Impact of Gynoid Fat Distribution and Free Testosterone on Circulating Levels of N-Terminal ProBrain Natriuretic Peptide (NT-proBNP) in Humans. J Clin Med. 2019;9(1).

14. Chlabicz M, Jamiolkowski J, Paniczko M, Sowa P, Szpakowicz M, Lapinska M, et al. ECG Indices Poorly Predict Left Ventricular Hypertrophy and Are Applicable Only in Individuals With Low Cardiovascular Risk. J Clin Med. 2020;9(5).

15. Pavot W, Diener E, Colvin CR, Sandvik E. Further validation of the Satisfaction with Life Scale: evidence for the cross-method convergence of well-being measures. J Pers Assess. 1991;57(1):14961.

16. Janssen MF, Birnie E, Bonsel GJ. Quantification of the level descriptors for the standard EQ-5D threelevel system and a five-level version according to two methods. Qual Life Res. 2008;17(3):463-73.

17. Rosmond R, Lapidus L, Marin P, Bjorntorp P. Mental distress, obesity and body fat distribution in middle-aged men. Obes Res. 1996;4(3):245-52.

18. Rosmond R, Bjorntorp P. Psychiatric ill-health of women and its relationship to obesity and body fat distribution. Obes Res. 1998;6(5):338-45.

19. Tang AL, Thomas SJ, Larkin T. Cortisol, oxytocin, and quality of life in major depressive disorder. Qual Life Res. 2019;28(11):2919-28.

20. Calzo JP, Corliss HL, Blood EA, Field AE, Austin SB. Development of muscularity and weight concerns in heterosexual and sexual minority males. Health Psychol. 2013;32(1):42-51.

21. Cafri G, Thompson JK, Ricciardelli L, McCabe M, Smolak L, Yesalis C. Pursuit of the muscular ideal: Physical and psychological consequences and putative risk factors. Clin Psychol Rev. 2005;25(2):215-39.

22. Pope HG, Jr., Gruber AJ, Mangweth B, Bureau B, deCol C, Jouvent R, et al. Body image perception among men in three countries. Am J Psychiatry. 2000;157(8):1297-301.

23. Sullivan PW, Ghushchyan V, Wyatt HR, Wu EQ, Hill JO. Impact of cardiometabolic risk factor clusters on health-related quality of life in the U.S. Obesity (Silver Spring). 2007;15(2):511-21.

24. Baceviciene M, Reklaitiene $R$, Tamosiunas A. Effect of excess body weight on quality of life and satisfaction with body image among middle-aged Lithuanian inhabitants of Kaunas city. Medicina (Kaunas). 2009;45(7):565-73.

25. De Bucy C, Guignat L, Niati T, Bertherat J, Coste J. Health-related quality of life of patients with hypothalamic-pituitary-adrenal axis dysregulations: a cohort study. Eur J Endocrinol. 2017;177(1):18.

26. Kim M, Kim J, Won CW. Association between involuntary weight loss with low muscle mass and health-related quality of life in community-dwelling older adults: Nationwide surveys (KNHANES 2008-2011). Exp Gerontol. 2018;106:39-45.

27. Balogun S, Winzenberg T, Wills K, Scott D, Jones G, Callisaya ML, et al. Prospective associations of low muscle mass and strength with health-related quality of life over 10-year in community-dwelling older adults. Exp Gerontol. 2019;118:65-71. 
28. Jokela M, Hamer M, Singh-Manoux A, Batty GD, Kivimaki M. Association of metabolically healthy obesity with depressive symptoms: pooled analysis of eight studies. Mol Psychiatry. 2014;19(8):9104.

29. Guedes EP, Madeira E, Mafort TT, Madeira M, Moreira RO, Mendonca LM, et al. Body composition and depressive/anxiety symptoms in overweight and obese individuals with metabolic syndrome. Diabetol Metab Syndr. 2013;5(1):82.

30. Moon JH, Kong MH, Kim HJ. Low Muscle Mass and Depressed Mood in Korean Adolescents: a Cross-Sectional Analysis of the Fourth and Fifth Korea National Health and Nutrition Examination Surveys. J Korean Med Sci. 2018;33(50):e320.

31. Heo JE, Shim JS, Song BM, Bae HY, Lee HJ, Lee E, et al. Association between appendicular skeletal muscle mass and depressive symptoms: Review of the cardiovascular and metabolic diseases etiology research center cohort. J Affect Disord. 2018;238:8-15.

32. Noh HM, Park YS. Handgrip strength, dynapenia, and mental health in older Koreans. Sci Rep. 2020;10(1):4004.

33. Campbell S, Marriott M, Nahmias C, MacQueen GM. Lower hippocampal volume in patients suffering from depression: a meta-analysis. Am J Psychiatry. 2004;161(4):598-607.

34. Mousavi K, Jasmin BJ. BDNF is expressed in skeletal muscle satellite cells and inhibits myogenic differentiation. J Neurosci. 2006;26(21):5739-49.

35. Maes M, Ruckoanich P, Chang YS, Mahanonda N, Berk M. Multiple aberrations in shared inflammatory and oxidative \& nitrosative stress (IO\&NS) pathways explain the co-association of depression and cardiovascular disorder (CVD), and the increased risk for CVD and due mortality in depressed patients. Prog Neuropsychopharmacol Biol Psychiatry. 2011;35(3):769-83.

36. Alshehri T, Boone S, de Mutsert R, Penninx B, Rosendaal F, le Cessie S, et al. The association between overall and abdominal adiposity and depressive mood: A cross-sectional analysis in 6459 participants. Psychoneuroendocrinology. 2019;110:104429.

37. Rivenes AC, Harvey SB, Mykletun A. The relationship between abdominal fat, obesity, and common mental disorders: results from the HUNT study. J Psychosom Res. 2009;66(4):269-75.

38. Hassan MK, Joshi AV, Madhavan SS, Amonkar MM. Obesity and health-related quality of life: a cross-sectional analysis of the US population. Int J Obes Relat Metab Disord. 2003;27(10):1227-32.

\section{Figures}


Dependent variable: SWLS

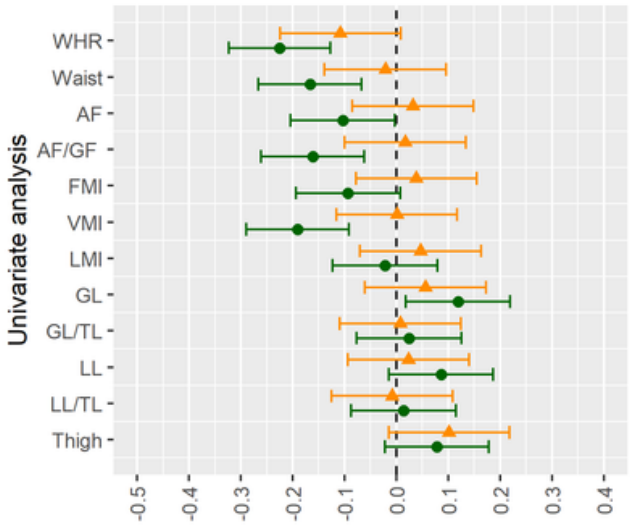

Dependent variable: EQ-VAS

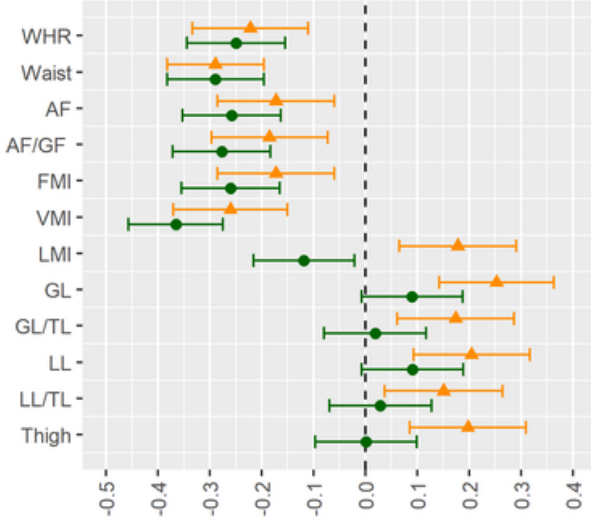

Dependent variable: BDI

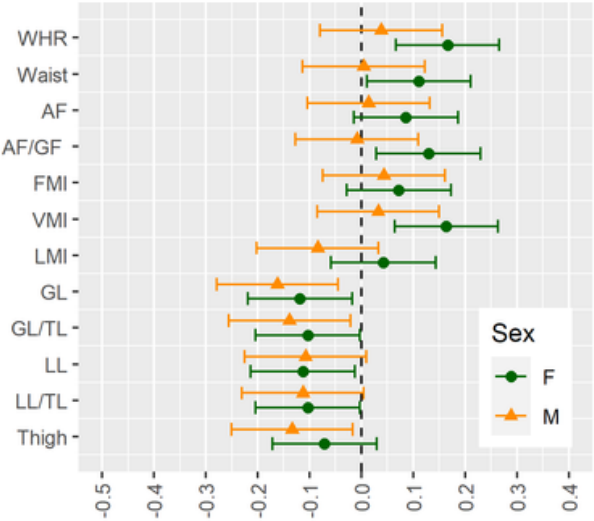

Figure 1

Univariate linear regression analysis between body composition and subjective well-being scores in nonobese individuals Abbreviations: SWLS: Satisfaction With Life Scale; EQ-VAS: Euro Quality of Life Visual Analogue Scale; BDI: Beck Depression Inventory; WHR: waist-hip ratio; AF: android fat; AF/GF: android fat/gynoid fat; FMI: fat mass index; VMI: visceral mass index; LMI: lean mass index; GL: gynoid lean; GL/TL: gynoid lean/total lean; LL: legs lean; LL/TL: legs lean/total lean.

Dependent variable: SWLS
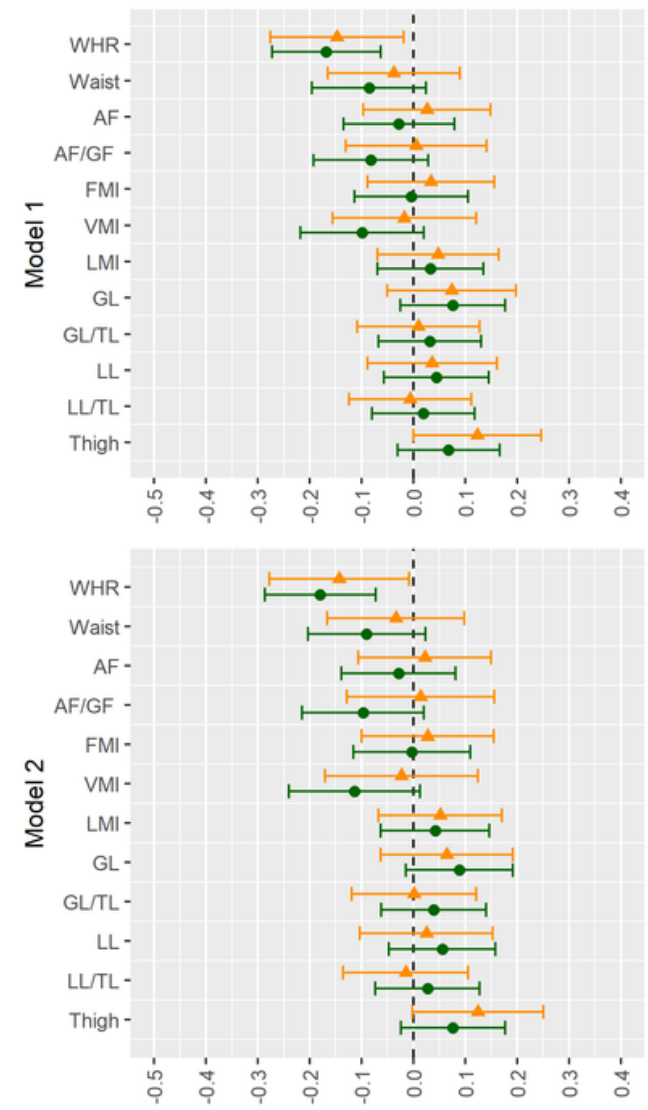

Dependent variable: EQ-VAS
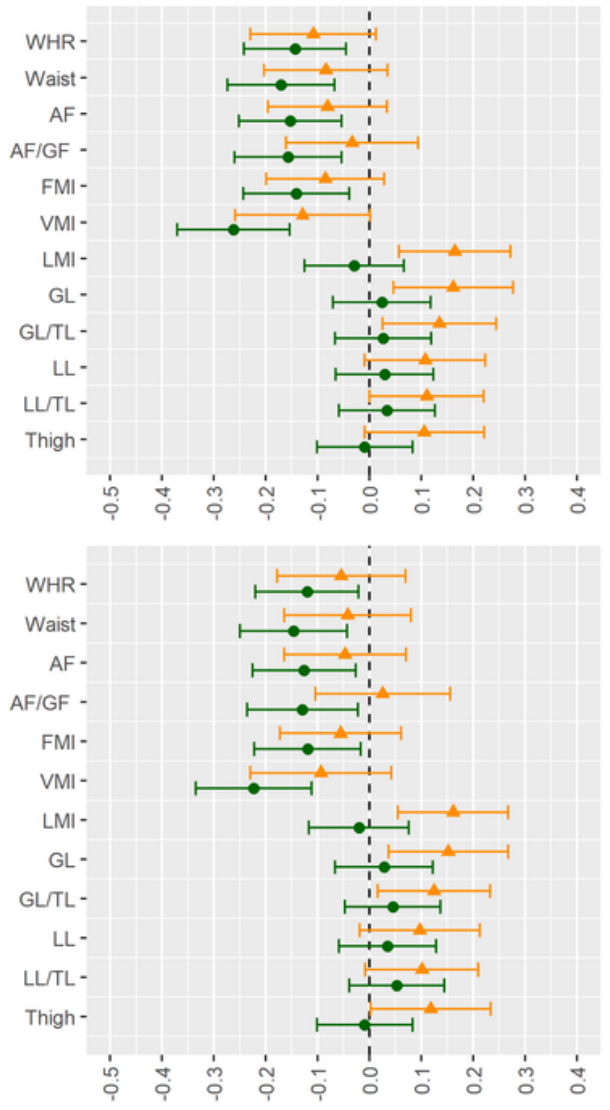

Dependent variable: BDI
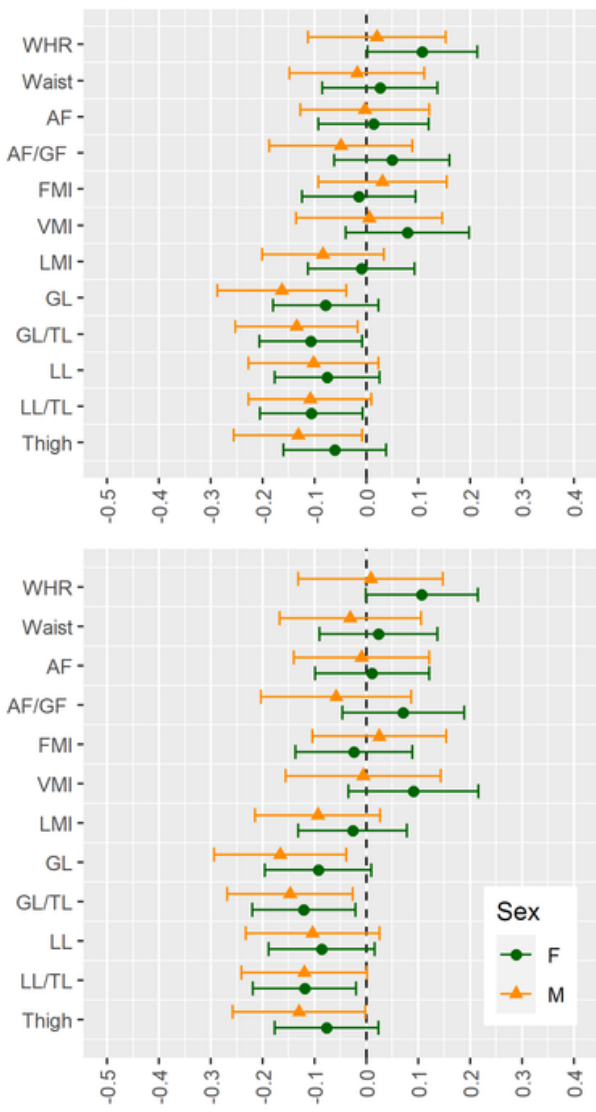

Figure 2 
Multivariable linear regression analysis between body composition and subjective well-being scores in non-obese individuals Model 1: adjusted for age Model 2: adjusted for age, history of cardiovascular diseases (i.e. arterial hypertension, atrial fibrillation, myocardial infarction, coronary heart disease, peripheral artery disease, stroke) and history of diabetes mellitus Abbreviations: SWLS: Satisfaction With Life Scale; EQ-VAS: Euro Quality of Life Visual Analogue Scale; BDI: Beck Depression Inventory; WHR: waist-hip ratio; AF: android fat; AF/GF: android fat/gynoid fat; FMI: fat mass index; VMI: visceral mass index; LMI: lean mass index; GL: gynoid lean; GL/TL: gynoid lean/total lean; LL: legs lean; LL/TL: legs lean/total lean.
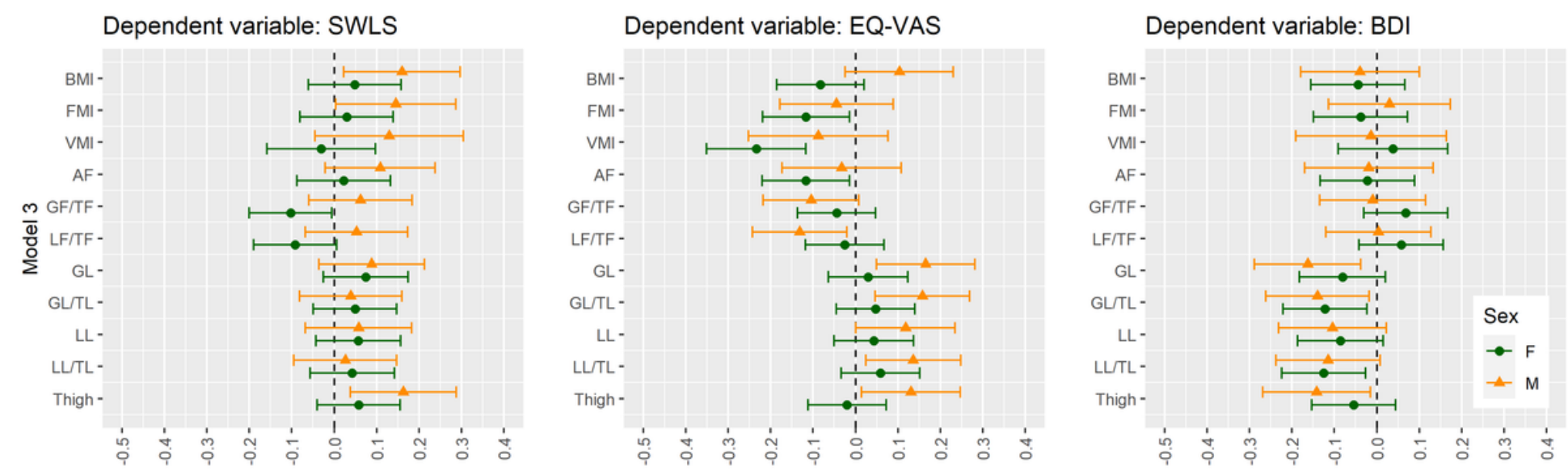

Figure 3

Multivariable linear regression analysis between body composition and subjective well-being scores in non-obese individuals Model 3: adjusted by age and WHR Abbreviations: SWLS: Satisfaction With Life Scale; EQ-VAS: Euro Quality of Life Visual Analogue Scale; BDI: Beck Depression Inventory; BMI: body mass index; FMl: fat mass index; VMI: visceral mass index; AF: android fat; GF/TF: gynoid fat/total fat; LF/TF: legs fat/total fat; GL: gynoid lean; GL/TL: gynoid lean/total lean, LL: legs lean; LL/TL: legs lean/total lean.

\section{Supplementary Files}

This is a list of supplementary files associated with this preprint. Click to download.

- Supplementarymaterial.docx 